\title{
Optimum Level of Partial Replacement of Cement with Ground Rice Husk Ash (GRHA) in Concrete
}

\author{
K. Arulkumaran, S. Suthan, A. Nishanthini, T.M. Pallewatta and D.A.R. Dolage
}

\begin{abstract}
For Rice Husk Ash (RHA) to be effective as a pozzolana, the fraction of Silica in amorphous state which exhibits high reactivity should be maximized by controlled burning. Due to practical difficulties, RHA produced in power plants and brick kilns in most parts of Sri Lanka does not contain significant fractions of amorphous Silica and thus have not shown high replacement potential of Cement in mortar or concrete. Thus, this study focussed on grinding RHA with high crystalline Silica content with the intention of producing higher reactive particle surface area to be used for partially replacing Cement in concrete. Main objective of the study was to find optimum partial replacement fraction of Cement by Ground Rice Husk Ash (GRHA) in concrete in terms of compressive strength.
\end{abstract}

For the study, RHA samples from brick kilns around Anuradhapura, where higher burning temperatures are used, were collected and ground in a ball mill for a fixed duration for the transformation into GRHA with a similar fineness as Cement. Prescribed concrete mix proportions were used with Cement replaced by GRHA. Standard concrete cubes were tested for compressive strength and other related tests, such as tensile strength, permeability and heat of hydration, were conducted to check for deviations. These studies revealed that a $35 \%$ replacement of Cement by GRHA is the optimum value to satisfy relevant parameters of the prescribed concrete mix.

Keywords: $\quad$ Pozzolana, Concrete, Rice husk ash, Carbon footprint

\section{Introduction}

Residual ash after burning of Rice Husk, which is a by-product of Rice production, is a granular waste that has received attention of the construction material sector for some time. Due to its exhibited pozzolanic properties, some attempts have been made in rice producing countries to use Rice Husk Ash (RHA) for partial replacement of Hydraulic Cement in concrete and mortar production [2], [9], [12], [13], [16].

Using Rice Husk Ash to partially replace Cement provides several advantages, such as improved workability and durability properties in the produced mortar or concrete coupled with benefits related to the preservation of environment by reduction of waste disposal. However, the most significant benefit is the reduction of Carbon Footprint in construction, derived by lower usage of Hydraulic Cement.

The total land area under paddy cultivation in Sri Lanka is estimated to be about 1,040,954 hectares [5]. Rice production of the country has increased from about 2.2 million metric tons to 4.4 million metric tons over a period of 20 years [6]. In the processing of the rice seed for dietary consumption, the husk is removed, which is about $20 \%$ in weight, as a by-product which is used as a fuel for thermal power generation, clay brick burning, etc. The residual RHA,

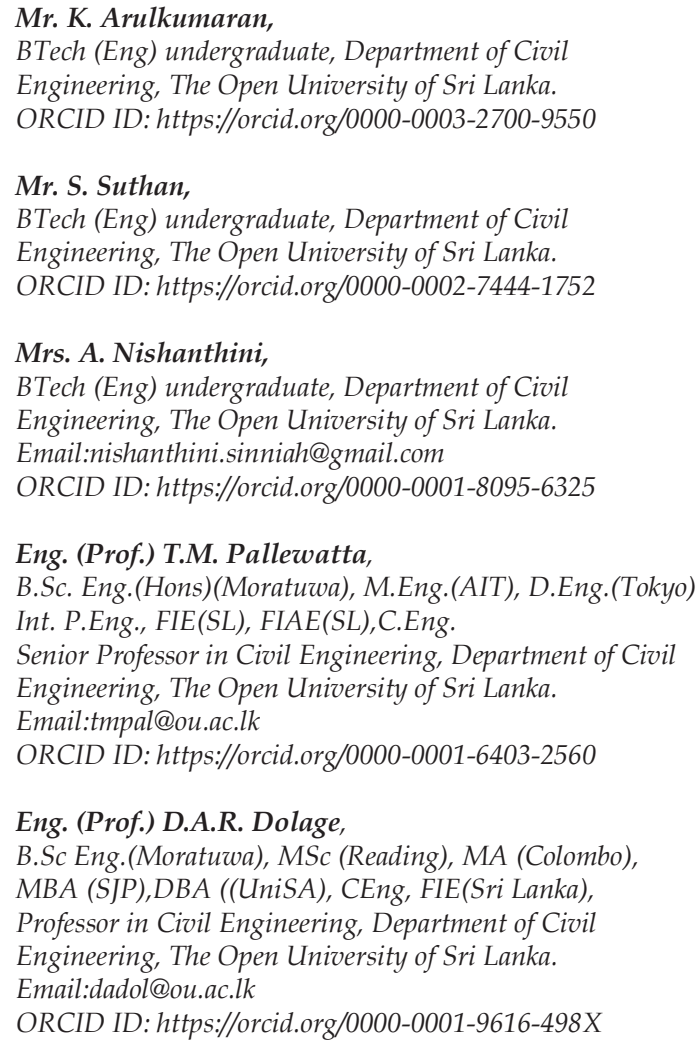


known to exhibit pozzolanic properties, between $20 \%-25 \%$ by weight of husk is available to be utilized in an effective and sustainable way.

Pozzolanic characteristic of a material which turns it into a cementitious binder under the influence of hydration products of hydraulic cements, depends on the following;
1. Silica $\left(\mathrm{SiO}_{2}\right)$ content
2. Silica crystallization phase
3. Size and surface area of Silica particles

In addition to above, the RHA should only contain as small as possible amount of residual carbon, as carbon reduces the binding properties RHA as a pozzolana.

The first factor of the Silica content is determined by the mineral composition of the optimized RHA in terms of pozzolanic activity, which can be achieved by controlled burning or grinding. The ash, produced by control burning of rice husk between $700{ }^{\circ} \mathrm{C}$ and $750{ }^{\circ} \mathrm{C}$ incinerating temperature for 1 hour, transforms the silica content of the ash into amorphous phase [9]. The reactivity of amorphous silica is directly proportional to the specific surface area of ash particles.

However, in practice, it has been evident that burning temperatures vary from this optimum band. Since in most cases of burning (brick kilns \& power plants) the temperatures go beyond $750{ }^{\circ} \mathrm{C}$ of the optimum range [9], attention had been paid by previous researchers [10], [12] to grind the RHA containing a high proportion of crystalline Silica in a bid to increase reactivity.

In a previous study [10] RHA ground in a ball mill was used to partially replace Cement in cement/sand block making up to $25 \%$ with success. Hence, this study was aimed at using optimally ball-mill ground RHA in partially replacing Cement for commonly specified prescribed concrete mix of ST-5 according to BS 5328 [4], to ascertain the optimum replacement level maintaining the strength, durability and workability.

\section{Study of Literature}

Rice Husk is a by product of rice milling industry and at present around 0.8 million metric tons of husk is produced per year [6]. Rice Husk is reduced to RHA by burning, which is around $18 \%$ by weight of the former.
In RHA, $80-85 \%$ by weight is Silica. It is essentially a waste material resulting in disposal problems in rice processing areas. However, according to the chemical properties of RHA, it could be considered as a pozzolana for partial replacement of hydraulic cement as a binder.

\subsection{Properties of RHA}

Typical physical and chemical properties of RHA are given in Table 1 and Table 2, respectively [1];

\section{Table 1 - Physical Properties of RHA}

\begin{tabular}{|l|l|}
\hline \multicolumn{1}{|c|}{ Property } & \multicolumn{1}{c|}{ Value } \\
\hline Specific gravity & $2.05-2.3$ \\
\hline Bulk density & $1.86\left(\mathrm{~g} / \mathrm{cm}^{3}\right)$ \\
\hline Colour & Grey \\
\hline Odour & Odourless \\
\hline Particle size & $45 \mathrm{Microns}-$ means \\
\hline Blaine fineness & $1400\left(\mathrm{~cm}^{2} / \mathrm{g}\right)$ \\
\hline Shape/Texture & Irregular/Rough \\
\hline
\end{tabular}

Table 2 - Chemical Composition of RHA

\begin{tabular}{|c|c|}
\hline Compound & Percentage in RHA \\
\hline $\mathrm{CaO}$ & 0.5 \\
\hline $\mathrm{SiO}_{2}$ & 87.3 \\
\hline $\mathrm{Al}_{2} \mathrm{O}_{3}$ & 0.2 \\
\hline $\mathrm{Fe}_{2} \mathrm{O}_{3}$ & 0.3 \\
\hline $\mathrm{MgO}$ & 0.3 \\
\hline $\mathrm{Na}_{2} \mathrm{O}$ & 1.0 \\
\hline $\mathrm{K}_{2} \mathrm{O}$ & 3.2 \\
\hline
\end{tabular}

The pozzolanic activity of RHA can simply be described as follows: Hydration reactions of component compounds in hydraulic Cements produce excess Calcium Hydroxide $\left(\mathrm{Ca}(\mathrm{OH})_{2}\right)$. When RHA containing active Silica $\left(\mathrm{SiO}_{2}\right)$ is combined with $\mathrm{Ca}(\mathrm{OH})_{2}$, the result is the production of Calcium Silicate Hydrate (C-S-H) which contributes to higher strength in the hydrated Cement matrix. In addition, fine RHA particles further contribute to the strength of the Cement matrix by acting as a micro filler.

\subsection{Sulphate Resistance of Concrete Made with RHA}

Durability of concrete is defined as its ability to resist deterioration, thereby being capable of maintaining its original quality and form once it has been exposed to the environment of its use. The deterioration of concrete can be caused by either internal chemical reaction from the constituents of concrete or external attacks from chemicals such as sulphates.

Sulphate attack, which is a major cause of the lack of durability in concrete, is the loss of 
strength by reaction with hydration product Calcium Hydroxide $\left[\mathrm{Ca}(\mathrm{OH})_{2}\right]$ and strength giving Calcium Silicate Hydrate (C-S-H). When Sodium Sulphate $\left(\mathrm{Na}_{2} \mathrm{SO}_{4}\right)$ attacks $\mathrm{Ca}(\mathrm{OH})_{2}$. expansive ettringites are formed as needle shaped crystals, causing volume increases up to $125 \%$ which could generate tensile stresses resulting in cracks.

Though decalcification of C-S- $\mathrm{H}$ in $\mathrm{Na}_{2} \mathrm{SO}_{4}$ attack is made negligible, Magnesium Sulphate $\left(\mathrm{MgSO}_{4}\right)$ attack has been reported to affect C-S$\mathrm{H}$, converting it to non cementitious Magnesium Silicate Hydrate (M-S-H). It is known that low sulphate resistance is caused by low levels of Silica $\left(\mathrm{SiO}_{2}\right)$, and high levels of sulphates $\left(\mathrm{SO}_{4}\right)$, iron $\left(\mathrm{Fe}_{2} \mathrm{SO}_{3}\right), \mathrm{Ca}(\mathrm{OH})_{2}$, and aluminate $\left(\mathrm{C}_{3} \mathrm{~A}\right)$. It has been suggested that Supplementary Cementitious Materials (SCMs) such as pozzolanic RHA react with by-products of hydration of Cement, help to dilute $\mathrm{C}_{3} \mathrm{~A}$ and remove $\mathrm{Ca}(\mathrm{OH})_{2}$ by converting it into C-S-H, reducing ettringite formation [2].

SCMs such as RHA also reduce the permeability of concrete by the packaging effect of their un-reacted particles.

\subsection{Previous Studies on RHA Blended with Cement}

Through compressive strength tests on mortar cubes with Cement replaced by RHA at five levels $(10,20,30,40$ and $50 \%)$, after curing to the age of $1,3,7,14$ and 28 days, the researchers [7] found that Cement replacement by RHA between $10-20 \%$ is possible.

Using RHA obtained from Vietnam and India, key properties of high strength concrete with RHA pertaining to workability, density, compressive strength, water and chloride permeability resistances, were investigated by researchers [11] and has concluded that reasonable improvements in these properties could be obtained, especially with RHA from India.

A research carried out on the topic of use of RHA blended Cement to manufacture cement sand cellular blocks [8], shows that the maximum compressive strength is observed at a binder sand ratio 1:3. The compressive strength decreased when increasing the binder sand ratio, and when RHA replaced OPC, the maximum compressive strength was observed at $5 \%$ replacement level of RHA. The study found that the optimum mix proportions to satisfy standards were at binder sand ratio of
1:5, water binder ratio of 0.5 and RHA replacement level of $5 \%$. Similar pattern has been observed with a study [9] on the use of Rice Husk Ash blended cement to produce cement sand blocks at optimum level of 15\% cement replacement for compressive strength.

The study on characteristics of masonry block manufactured with Rice Husk Ash and lime [15] investigated potential use of RHA with lime to manufacture masonry blocks. Compressive strength, water absorption and thermal performance of blocks manufactured with RHA and lime have been investigated. There were four different percentages of RHA $(0,5,10,15$ and 20) used with constant percentage of lime content of $10 \%$ for the experimental phases. Optimum 28 day compressive strength was found at the level of $10 \%$ RHA with thermal conductivity of RHA lime-based block lower, as compared with a conventional block.

A research study on a different aspect of usage of RHA [3], has conducted tests on Paddy Husk Ash stabilized soil bricks. The study investigated the performance of soil bricks stabilized using RHA and lime and the optimal percentage of lime that can be mixed with RHA in order to gain maximum strength and durability. As a result, optimum lime content to stabilize soil bricks was observed to be $10 \%$ of the RHA.

A study [1] on element analysis of Rice Husk Ash obtained from different varieties of rice grown in Polonnaruwa District, researchers identified the elements present in different varieties of RHA, and the amount of silica which is industrially important in pure form. This study concluded that the number of elements present in $\mathrm{RH}$ depends on the rice variety, soil and climate condition.

A study, very close to the objectives of this research, had been carried out by Dolage et al. [10] to obtain RHA samples by controlled burning and grinding in ball mills to partially replace Cement in cement/sand cellular blocks. The study revealed that up to $30 \%$ replacement of Cement with GRHA would give above the required standard strength to cellular blocks.

An experimental investigation on the properties of concrete containing Rice Husk Ash with different finenesses [16], had also used three different replacement percentages of RHA in concrete $(10 \%, 20 \%$ and $30 \%$ by mass of 
Cement). In this study, tests for compressive strength, tensile strength and surface water absorption and a comparative study on chemical and physical properties had been carried out. As a result, a significant improvement on the compressive strength at early stage has been identified and optimum strength had been achieved at 20\% replacement of RHA by mass of cement. This study again confirms that the performance of the concrete is dependent on the fineness of the RHA where the fineness of the RHA increased the compressive strength of concrete.

\section{Methods and Materials used for the Research}

This research study is essentially based on experimental work and as such the materials and methods were carefully selected to ensure accuracy of the results.

\subsection{Materials Used}

For concrete mixes OPC conforming to Sri Lankan standard SLS 107: 2015 was utilised in preparing the binder. Clean river sand passing through $2.65 \mathrm{~mm}$ British Standard test sieve was used as fine aggregate. Crushed granite aggregate passing through $20 \mathrm{~mm}$ sieve was used as coarse aggregate.

RHA samples were collected from Mihintale, Rambawa and Saliyapura brick kilns in Anuradhapura District. These RHA samples were packed in polythene bags to prevent movement of moisture and transported to the grinding facility.

Samples were ground in a ball mill in $10 \mathrm{~kg}$ batches. Each $10 \mathrm{~kg}$ of RHA sample was ground in steps of five minute intervals by using $100 \mathrm{~kg}$ of steel balls in the mill. After each five minute grinding, a representative sample was taken and passed through BS Sieve set and retaining fractions were noted. These retaining fractions in the fine sieves were compared with those of OPC cement to arrive at the optimum grinding time.

\subsection{Composition of Concrete Mixes}

The concrete mixes were prepared by adding the materials in the proportions specified for prescribed concrete mixes as outlined in the Code BS 5328 [4] as ST-5. The target cube compressive strength of concrete adopted was $25 \mathrm{~N} / \mathrm{mm}^{2}$ for the OPC control mix (0\% GRHA). Content of Cement in the prescribed mix was partially replaced with GRHA at the required percentages and the cubes were cast and cured using standard procedures and methods. Concrete cubes were submerge-cured until the time for compression testing. Table 3 shows the details of mix design to each concrete sample per $1.0 \mathrm{~m}^{3}$. Water/Cement ratio was maintained at 0.55 for all mixes. For each of the mix proportions in Table 3, seven concrete cubes were cast, total amounting to 63 cubes.

Table 3 - Prescribed Mix Proportions Per $1 \mathrm{~m}^{3}$ Volume of Concrete Mixes

\begin{tabular}{|c|c|c|c|c|}
\hline 总 & 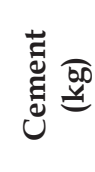 & 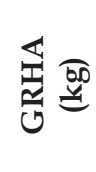 & لَّ & 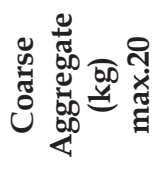 \\
\hline 0 & 370 & 0 & 708 & 1062 \\
\hline 15 & 314.5 & 55.5 & 708 & 1062 \\
\hline 20 & 296 & 74 & 708 & 1062 \\
\hline 25 & 277.5 & 92.5 & 708 & 1062 \\
\hline 30 & 259 & 111 & 708 & 1062 \\
\hline 35 & 240.5 & 129.5 & 708 & 1062 \\
\hline 40 & 222 & 148 & 708 & 1062 \\
\hline 45 & 203.5 & 166.5 & 708 & 1062 \\
\hline 50 & 185 & 185 & 708 & 1062 \\
\hline
\end{tabular}

The main objective of this research study is to find the optimum percentage of GRHA in replacement of cement with the help of compressive strength testing.

According to the findings of the literature review [12], the optimum percentage of RHA in a concrete mix is $15 \%$. Therefore, experimental works were initiated with a concrete mix with $15 \%$ of GRHA and increased in steps of $5 \%$, up to $50 \%$, to find the optimum compressive strength of concrete cubes and other related mechanical parameters such as Tensile strength, Corrosion resistance, Water absorption \& measurement of heat generation due to hydration.

\section{Results and Discussion}

\subsection{Chemical Properties of GRHA}

The tests for chemical composition of GRHA were carried out in INSEE Research Laboratory at Galle. Representative samples were obtained after thoroughly mixing RHA samples collected from different locations from the Anuradhapura District. The test results are tabulated in Table 4. It is noted that the amounts of Calcium Oxide and Aluminum Oxide are significantly higher than the values in Table 2, which could be due to change in 
varieties of rice grown, which could influence the composition of respective RHA.

Table 4 - Chemical composition of GRHA

\begin{tabular}{|c|c|}
\hline Compound & Percentage in GRHA \\
\hline $\mathrm{CaO}$ & 5.2 \\
\hline $\mathrm{SiO}_{2}$ & 82.7 \\
\hline $\mathrm{Al}_{2} \mathrm{O}_{3}$ & 3.8 \\
\hline $\mathrm{Fe}_{2} \mathrm{O}_{3}$ & 1.2 \\
\hline $\mathrm{MgO}$ & 0.9 \\
\hline $\mathrm{SO}_{3}$ & 0.1 \\
\hline
\end{tabular}

4.2 Optimum Grinding Time in the Laboratory

The RHA sample was ground in a ball mill with the grinding progress monitored using sieve analysis. A RHA sample, $10 \mathrm{~kg}$ in weight, was mixed with $100 \mathrm{~kg}$ of $17 \mathrm{~mm}$ dia. cast iron balls, and grinding was carried out in five minute steps. After each step, a sample was taken and sieved through a $0.045 \mathrm{~mm}$ sieve with the retained fraction noted.

The optimum grinding time had to be short enough so that power used for grinding is kept at a minimum, while the fineness of the sample achieved a value close to that of the typical value for Cement. In terms of retained fraction in the $0.045 \mathrm{~mm}$ sieve, Cement was typically $6 \%$.

The closest match to this was obtained with a grinding time of 20 minutes with RHA, giving a retained fraction of $7 \%$ as shown by the curve in Figure 1.

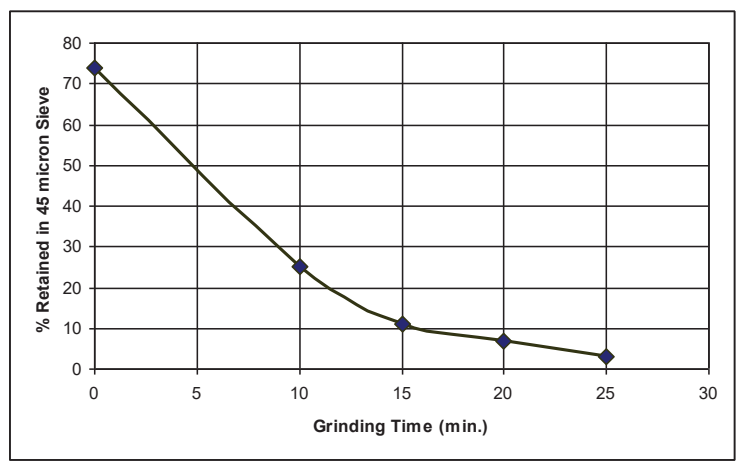

Figure 1 - Retained fraction of GRHA (\%) in $0.045 \mathrm{~mm}$ sieve with respect to grinding time

However, a grinding time of 15 minutes resulted in $11 \%$ retained fraction which, as compared with the starting state of almost $75 \%$ retaining of RHA, is a substantial reduction in particle size.

Further, it was observed that the rate of reduction of particle size with grinding time sharply reduced after 15 minutes of grinding.
Based on the above facts and considering the power consumed for grinding the practical optimum grinding time was decided as 15 minutes.

4.3 Fineness of Ground Rice Husk Ash An air permeability test was carried out to find the fineness of GRHA relative to known OPC fineness. The test procedure is based on ASTM C204. According to the air permeability test results, the fineness of GRHA is $3735 \mathrm{~cm}^{2} / \mathrm{g}$, which is higher than the fineness of OPC Cement $\left(3300-3400 \mathrm{~cm}^{2} / \mathrm{g}\right)$ used. This higher surface area was expected to create better reactivity of GRHA with the hydration products of Cement, thus resulting in higher pozzolanic activity.

4.4 Compressive Strength and Slump Test As described previously, cube samples for different mix combinations were cast, cured and tested for compressive strength at different ages. The results of 28 day averaged compression strength tests on cube samples which characterize the concrete grade are presented in Table 5.

Table 5 - Results of Average Compressive Strength

\begin{tabular}{|c|c|c|}
\hline $\begin{array}{c}\text { Percentage } \\
\text { of Cement }\end{array}$ & $\begin{array}{c}\text { Percentage } \\
\text { of GRHA }\end{array}$ & $\begin{array}{c}\text { Average } \\
\text { Compressive } \\
\text { Strength after 28 } \\
\text { days (N/ } \mathbf{~ m m}^{2} \text { ) }\end{array}$ \\
\hline 100 & 0 & 39.90 \\
\hline 85 & 15 & 41.98 \\
\hline 80 & 20 & 45.14 \\
\hline 75 & 25 & 43.99 \\
\hline 70 & 30 & 44.40 \\
\hline 65 & 35 & 45.98 \\
\hline 60 & 40 & 43.56 \\
\hline 55 & 45 & 44.64 \\
\hline 50 & 50 & 38.10 \\
\hline
\end{tabular}

It is interesting to note from Table 5 that, even up to $45 \%$ of Cement replacement with GRHA, average strength of concrete has remained above that of the control sample with $0 \%$ Cement replacement. The trend is clear that, up to $35 \%$ Cement replacement by GRHA, the strength continues to increase followed by a higher rate of decrease beyond this value.

It is further noted that even with $45 \%$ replacement of Cement with GRHA, the 28 day compressive strength values of concrete cubes are above the control sample with $0 \%$ replacement by GRHA. Figure 2 depicts the 
variation of cube compression strength with Cement replacement by GRHA for different ages of curing of concrete. The trends of compressive strength variation with Cement replacement, at different ages of testing, show an appreciable match, which stands to verify the accuracy of the results.

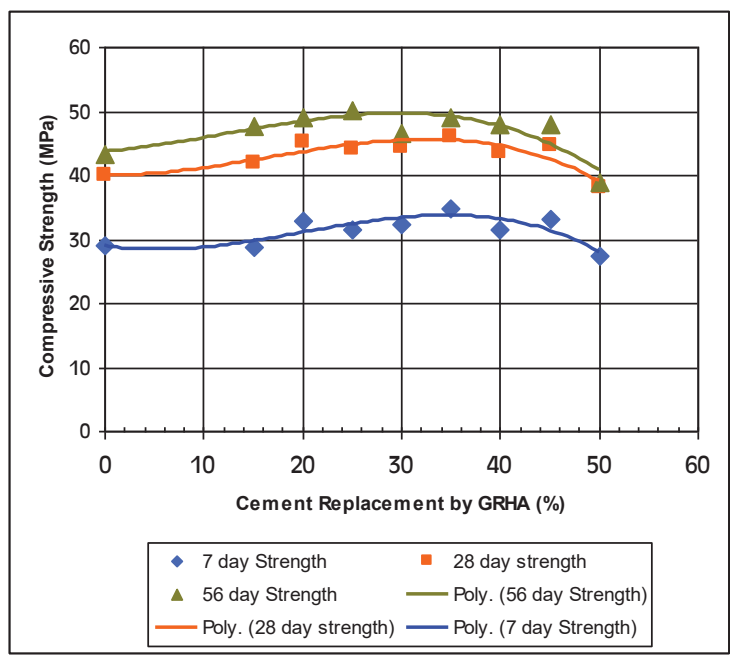

Figure 2 - Strength variation of Concrete with the replacement of Cement by GRHA at different ages

Due to increased fineness of GRHA particles more water is needed to lubricate the surfaces, as specific surface area of the GRHA particles is high. This phenomenon is clearly indicated by the loss of slump in the wet state of concrete mixes with increasing percentage of GRHA, while maintaining the same water:binder ratio as depicted in Figure 3. To bring back the workability, water content needs to be increased or, as an alternative, an admixture could be utilized.

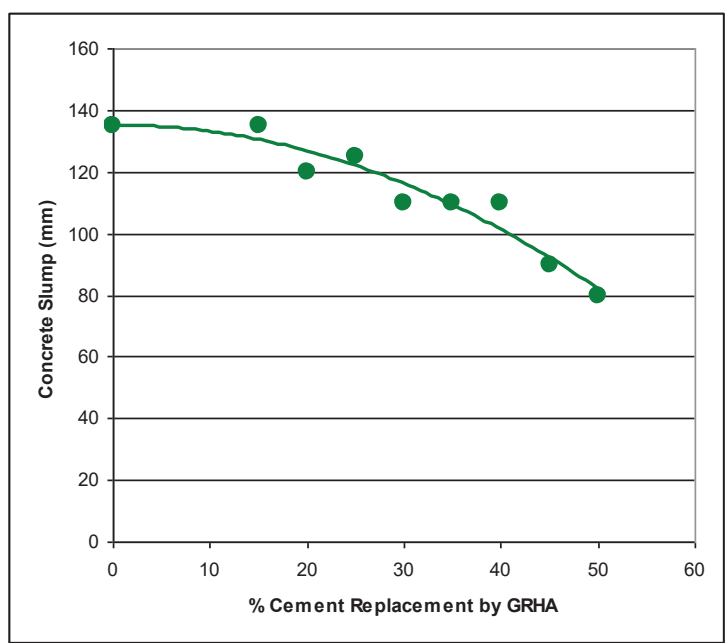

Figure 3 - Slump variation of mixes with increase in GRHA percentage
After ascertaining the optimum GRHA replacement the following tests were carried out, with both Cement replaced by 35\% GRHA and control test without GRHA (0\% GRHA), to ascertain any variations in other relevant physical properties as listed below;
1. Tensile strength
2. Corrosion
3. Water absorption
4. Heat of hydration

\subsection{Tensile Strength}

Tensile splitting tests were conducted on standard concrete test cylinders at 28 days for control ( $0 \%$ GRHA) and optimum replacement (35\% GRHA) with three samples each. Values of tensile strength were within $0.9 \%$ of each other and could be taken as closely comparing.

However, it should be noted that concrete with Cement replacement by 35\% GRHA produced marginally high splitting strength as compared to control concrete. Though the difference is too small to be conclusive, this result is in line with the concept that higher compressive strength is associated with higher tensile strength.

\subsection{Corrosion Test}

Accelerated corrosion tests, by an electrical potential applied to a reinforcing steel bar embedded in concrete according to ASTM A 380 , were conducted for control concrete $(0 \%$ Cement replacement) and optimum mix concrete (35\% Cement replacement by GRHA). Table 6 gives the results of four tests conducted.

Table 6 - Accelerated Corrosion Test Results

\begin{tabular}{|c|c|c|c|c|}
\hline No & $\begin{array}{c}\text { Fraction } \\
\text { of } \\
\text { GRHA } \\
\text { (\%) }\end{array}$ & $\begin{array}{c}\text { Weight of } \\
\text { steel } \\
\text { before } \\
\text { corrosion } \\
\text { (g) }\end{array}$ & $\begin{array}{c}\text { Weight } \\
\text { loss (g) }\end{array}$ & $\begin{array}{c}\text { Relative } \\
\text { weight } \\
\text { loss } \\
\mathbf{( \% )}\end{array}$ \\
\hline 1 & 0 & 89.00 & 3.00 & 3.37 \\
\hline 2 & 0 & 87.50 & 3.00 & 3.43 \\
\hline 3 & 35 & 88.50 & 3.00 & 3.39 \\
\hline 4 & 35 & 93.00 & 4.50 & 4.83 \\
\hline
\end{tabular}

According to ASTM, though all results fall in the "low range" for corrosion, it is indicative that concrete with GRHA produces marginally corrosion prone concrete than the control.

\subsection{Water Absorption}

Water absorption tests were conducted based on SLS 855 - Part 2 on concrete cubes. Tests done on six samples, two control samples and four samples with 35\% GRHA, show that the water absorption on the latter is $16 \%$ lower than the control concrete sample without Cement being replaced by GRHA. 
This is an interesting and expected finding as the slow reacting fines introduced into concrete as GRHA tend to gradually fill the micro-voids in concrete matrix, making it more impervious to water ingress.

\subsection{Measurement of Heat Generation due to Hydration}

This physical characteristic was investigated as it was expected that Cement, which is the primary heat generating source due to hydration, being replaced of by a slow reacting pozzolana (GRHA) would reduce the rate of heat generation in concrete.

The rate of heat generation due to hydration was checked for both control concrete and concrete with 35\% GRHA replacing Cement. The hydration process was carried out in an improvised calorimeter and the temperature value at every half a minute was recorded.

However, no significant variation in the heat generation rates could be observed between the two concrete mixes based on the two tests each that were conducted.

\section{Conclusions}

In this research study, RHA samples were taken from brick kilns in the Anuradhapura District and ground under uniform conditions to increase fineness and reactive surface area to be investigated in determining its effectiveness as a pozzolana. Prescribed concrete mixes of ST-5 for $25 \mathrm{~N} / \mathrm{mm}^{2}$ target mean strength were prepared with Ordinary Portland Cement (OPC) partially replaced with GRHA from $0 \%$ to $50 \%$ by weight. Concrete cubes were cast for ascertaining compressive strength of concrete mixes and other relevant properties. To determine the optimum Cement replacement ratio by GRHA, several experimental series were conducted and following conclusions are made through this experimental research study.

By varying the replacement of Cement as a binder by GRHA up to $50 \%$, it was identified in this study that the highest strength was achieved with a replacement fraction of 35\%, which was confirmed by compression test results at three curing ages of 7days, 28 days and 56 days. In addition to this observation, it was confirmed that grinding of RHA to finer fractions improved its reactivity as a pozzolana and consequently contributed very positively towards the strength of concrete. Though a decline in strength was observed when GRHA replacement went beyond 35\%, even at replacement level of $50 \%$ GRHA, the resulting concrete produced only marginally lower strength values than the control concrete with $0 \%$ GRHA. This is a very significant finding, positively indicating that Cement replaced even up to $50 \%$ by GRHA, which is a waste byproduct, could produce comparable strength concretes for the grade (Grade 25) investigated.

According to the results of compressive strength, this study concludes that 35\% replacement level of Cement by GRHA is the optimum level. Other relevant mechanical properties of concrete checked, in comparison with the control samples of $0 \%$ GRHA replacement, show good agreement in such a way that splitting tensile strength is marginally higher, corrosion resistance comparable, water absorption lower and heat of hydration comparable. Only a marginal loss of workability indicated by loss of slump in the fresh state of optimized concrete mix could be categorized as negative.

\section{Recommendations}

Since RHA is a fine grained waste material containing Silica, its arbitrary disposal will create serious environmental as well as health problems. Therefore, incorporation of RHA in a modified form of GRHA in concrete production is highly recommended as it generates benefits in two folds; firstly, while preventing environmental pollution and secondly, reducing carbon footprint in concrete production.

Further, reducing depletion of non-renewable raw material and fuel needed for production of Cement Clinker, GRHA, which is a renewable processed agricultural byproduct, can assist in sustainable construction.

Rice Husk Ash could be used in two ways to partially replace Cement in the construction industry. First is the methodology used in this study to grind RHA and partly use in place of Cement. The second more industrial level option is to inter-grind RHA with cement clinker and gypsum at the last manufacturing stage of Cement.

Further, GRHA could be made available in the local market in some form of packaging akin to Cement, so that appropriate proportions of GRHA could be blended with Cement for needed purposes. 


\section{References}

1. Ajaward, N. F., Rajendra, J. C. N. \& Perera, V. P. S., "Element Analysis of Rice Husk Ash Obtained From Different Varieties of Rice Grown in Polonnaruwa District", Annual Academic Sessions 2015, The Open University of Sri Lanka, ISSN 2012 9912, 2015.

2. Amitkumar, I. G. \& Abhay, S. W., (2015), “Use of Rice Husk Ash in Concrete", IOSR Journal of Mechanical and Civil Engineering (IOSR-JMCE) eISSN: 2278-1684,p-ISSN: 2320-334X, Vol. 12, Iss. 4, Ver. I, 2015, pp. 29-31.

3. Baskaran, K., Mallikarachchi, H. E. \& Jayawickrama, M., "Paddy husk Ash Stabilized Soil Bricks", International Conference on Sustainable Built Environment, Kandy Sri Lanka, 2012.

4. British Standard 5328: Part 2: 1997 "Method for Specifying Concrete Mixes".

5. "Census on Population \& Housing" Department of Census and Statistics, Sri Lanka., 2018.

6. Central Bank Annual Report 2016, Central Bank of Sri Lanka.

7. Dabai, M. U., Muhammad, C., Bagudo, B. U. \& Musa, A., "Studies on the Effect of Rice Husk Ash as Cement Admixture", Nigerian Journal of Basic and Applied Science, 2009, pp. 252-256.

8. Dolage, D. A. R., Ali Rajay, A. M. \& Parvatha keethan, A., "Use of Rice Husk Ash Blended Cement to Manufacture Cellular Masonry Blocks", $6^{\text {th }}$ International Conference on Structural Engineering and Construction Management, Kandy, Sri Lanka, 2015, pp. 148-154.

9. Dolage, D. A. R., Mylvaganam, K., Mayoorathan, P. \& Inparatnam, S., "Use of Rice Husk Ash Blended Cement to Produce Cement Sand Block", Journal of the Institution of Engineers, Sri Lanka, ENGINEER, Vol. XXXXIV, No.02, 2011, pp. 11-19.

10. Dolage, D. A. R., Pallewatta, T. M., Pragash, T., Chathurangani, J. T. H. \& Sellathurai, V., "Use of Ground Rice Husk Ash Blended Cement to Manufacture Cement Sand Cellular Blocks", $8^{\text {th }}$ International Conference on Structural Engineering and Construction Management, Kandy, Sri Lanka, 2017.

11. Dong, D. V., Huu, P. D. \& Lan, N. N., "Effect of Rice Husk Ash on Properties of High Strength Concrete" $3^{\text {rd }}$ Asian Concrete Federation Int. Conference in Vietnam, 2008, pp. 442-449.
12. Gaesan, K., Rajagopal, K. \& Thangavel, K., “Rice Husk ash Blended Cement: Assessment of Optimal Level of Replacement for Strength and Permeability Properties of Concrete", Journal of Construction and Building Materials, 2008, pp. 1675-1683.

13. Marthong, C., "Effect of Rice Husk Ash (RHA) as Partial Replacement of Cement on Concrete Properties", International Journal of Engineering Research \& Technology (IJERT), Vol. 01 Issue 6., 2012.

14. Perera, B. V. A., Madhushanka, K. G. S., De Silva, S. \& De Silva, G. S. Y., "Effect of Rice Husk Ash (RHA) on Structural Properties of Fired Clay Bricks", $6^{\text {th }}$ International Conference on Structural Engineering and Construction Management, Kandy, Sri Lanka, (2015), pp 131-136.

15. Pushpakumara, B. H. J. \& De Silva, S., "Characteristics of Masonry Blocks Manufactured with Rice Husk Ash (RHA) and Lime", Engineer, Vol. XXXXV, No. 03, 2012, pp. $1-10$.

16. Ramasamy.V, "Compressive Strength and Durability Properties of Rice Husk Ash Concrete", Korean Society of Civil Engineers Journal of Civil Engineering, 2012, pp. 93-100. 